\title{
Quando a potência dá prova de espírito: origem e lógica da justiça segundo Nietzsche*
}

\author{
Patrick Wotling**
}

\begin{abstract}
Resumo: Contrapondo-se à concepção tradicional de justiça, esse trabalho visa a expor a maneira pela qual Nietzsche interpreta esta noção, tendo como parâmetro avaliativo a doutrina da vontade de potência.

Palavras-chave: Nietzsche - justiça - potência - espírito - corpo
\end{abstract}

Sendo assim, não é aceitável - pois poderia induzir em erro - representar a justiça com uma balança na mão: o símbolo correto seria colocar a justiça numa balança, de modo que ela mantenha ambos os pratos em equilíbrio (Nachlass/FP 1886-7 5[82], KSA 12.221)1․

Há ainda lugar para a ideia de justiça numa reflexão que interpreta a vida como um processo de intensificação da potência e a caracteriza, por extensão, como sendo absolutamente desigualdade, expansão, injustiça? O texto póstumo colocado em epígrafe, que sintetiza os impasses do problema da justiça no ver de Nietzsche, não contesta, pondo em causa diretamente sua representação usual, a legitimidade mesma da noção de justiça? A interpretação

\footnotetext{
* "Quand la puissance fait preuve d'esprit. Origine et logique de la justice selon Nietzsche". In: WOTLING, P. (org.). Paris: Vrin, 2007, p. 113-140 @Librairie Philosophique J. Vrin. Tradução de Ivo da Silva Júnior.

** Professor da Universidade de Reims, Reims, França. E-mail: wotling@paris4.sorbonne.fr.

1 Trad. de Karina Jannini.
} 
Wotling, P.

da realidade como vontade de potência, que Nietzsche expõe nos detalhes, faz com que se alimente, em numerosos textos, a impressão desse impasse. Entre os mais relevantes figuram o § 259 de Para além de bem e mal e o $\$ 11$ da segunda dissertação da Genealogia da moral:

Falar de justo e injusto em si carece de qualquer sentido; em si, ofender, violentar, explorar, destruir não pode naturalmente ser algo "injusto", na medida em que essencialmente, isto é, em suas funções básicas, a vida atua ofendendo, violentando, explorando, destruindo, não podendo sequer ser concebida sem esse caráter" (GM/GM II 11, KSA 5.309-313, trad. PCS) ${ }^{1}$.

\section{Para além de bem e mal já precisava este ponto nos seguintes termos:}

Aqui devemos pensar radicalmente até o fundo, e aguardamo-nos de toda fraqueza sentimental: a vida mesma é essencialmente apropriação, ofensa, sujeição do que é estranho e mais fraco, opressão, dureza, imposição de formas próprias, incorporação e, no mínimo e mais comedido, exploração - mas por que empregar sempre essas palavras, que há muito estão marcadas de uma intenção difamadora? Também esse corpo no qual, conforme supomos acima, os indivíduos se tratam como iguais - isso ocorre em toda aristocracia sã -, deve, se for um corpo vivo e não moribundo, fazer a outros corpos tudo o que os seus indivíduos se abstêm de fazer uns aos outros: terá de ser a vontade de potência

1 Utiliza-se para os textos da obra Nietzsche as seguintes traduções: Nietzsche, F. Obras incompletas. Trad. Rubens Rodrigues Torres Filho. São Paulo: Nova Cultural, 1986 (Col. "Os Pensadores"); Assim falava Zaratustra. Trad. Mario da Silva. São Paulo: Bertrand Brasil, 1995; Humano, demasidado humano I. Trad. Paulo César Souza. São Paulo: Cia das Letras, 2000; Humano, demasidado humano II. Trad. Paulo César Souza. São Paulo: Cia das Letras, 2008; Genealogia da Moral. Trad. Paulo César Souza. São Paulo: Cia das Letras, 1998; Além do bem e do mal. Trad. Paulo César Souza. São Paulo: Cia das Letras, 1996. As indicações serão feitas, quando do uso destas edições, pelas iniciais dos nomes dos tradutores (NT).

204 | cadernos Nietzsche 32,2013 
encarnada, quererá crescer, expandir-se, atrair para si, ganhar predomínio - não devido a uma moralidade ou imoralidade qualquer, mas porque vive, e a vida é precisamente vontade de potência (JGB/BM 259, KSA 5.207-8, trad. PCS modificada).

Essas afirmações levariam a pensar, segundo Nietzsche, que a noção de justiça é apenas uma quimera inconsistente, uma interpretação à qual não corresponde nenhuma realidade, numa palavra, um destes conceitos que revelam a má filologia dos filósofos, como os conceitos de ser, de essência ou ainda o de vontade entendida como faculdade. Como se vê, numerosas leituras conduzem, de maneira mais ou menos correta, a interpretar a posição nietzschiana num viés naturalista e, por consequência, muito próxima daquela de Cálices, no Górgias: "segundo minha posição, a justiça consiste evidentemente em que o melhor tenha mais que o pior e em que o mais forte, mais que o menos forte. Em todo lugar é assim; é o que a natureza ensina (...). Se o mais forte domina o menos forte e é superior a ele, isto prova o que é o justo"2. A justiça humana, aquela que se exprime por meio da promulgação das leis, seria, para Nietzsche, uma simples astúcia eficaz que permite ao povo dominar os fortes, os mais potentes por natureza? Toda legitimidade estaria ao lado da natureza e a justiça, por sua vez, seria uma simples convenção que excluiria qualquer imposição natural?

O exame dos textos e das entrelinhas do pensamento nietzschiano mostra que as posições do filósofo são outras; mais ainda - e aqui se encontra certamente uma das surpresas que frequentemente o corpus de Nietzsche reserva - que a noção de justiça está bem legitimada e tem um sentido positivo; não só, um duplo sentido: um sentido jurídico e um sentido psicológico, que, no que tange a este último, não se impregna de preconceitos, mas, pelo

2 Górgias, 483 c-d. Trad. M. Canto-Sperber. Paris: GF-Flammarion, 1987. 
Wotling, P.

contrário, caracteriza-se pela ausência deles ou pela capacidade de ir contra propensões pessoais e preferências subjetivas na investigação dos homens e das coisas ${ }^{3}$.

Desta constatação, decorre uma série de problemas. De início, como justificar a justiça "jurídica" a partir de um contexto em que a realidade é pensada como lógica de intensificação de potência? Como conciliar estes dois sentidos da noção de justiça na reflexão de Nietzsche? A esse respeito, uma observação é necessária. Este segundo problema pode parecer secundário numa primeira aproximação, pois daria a entender que o mais importante é a harmonia do pensamento nietzschiano, a sua coerência interna, e não a pesquisa sobre a pertinência da noção de justiça. Cabe-nos mostrar que, ao contrário, é na profunda unidade destes dois sentidos aparentemente disjuntivos que se revela o verdadeiro estatuto da justiça na perspectiva nietzschiana.

Convém previamente atentar para um segundo ponto relativo ao primeiro sentido da noção de justiça, qual seja, o sentido jurídico estrito. É preciso distinguir, para deixar claro (mesmo que a lógica operante seja equivalente), o caso do indivíduo no interior da comunidade, em que a justiça tem a função de regular as relações intracomunitárias, e o caso dos conflitos entre comunidades consideradas no seu todo, em que, desta vez, a justiça tem papel regulador intercomunitário. O primeiro caso é estudado, no detalhe, na Genealogia da moral, mais precisamente do oitavo ao décimo primeiro parágrafo; o segundo é privilegiado pelos textos de Humano, demasiado humano I e II 4 .

Encontra-se, pois, no pensamento nietzschiano, uma situação complexa e paradoxal. Vê-se ao mesmo tempo, lado a lado, uma defesa e uma crítica da ideia de justiça. Convém então tentar delimitar estes dois campos.

3 No que diz respeito à justiça numa perspectiva psicológica, ver sobretudo o $§ 636$ do primeiro volume de Humano, demasiado humano (MA I/HHI 636, KSA 361-2).

4 Particularmente, "O andarilho e sua sombra", no segundo volume. 
Constata-se facilmente que aquilo que Nietzsche contesta, não é a justiça como tal, nem a pertinência de sua noção, mas certa interpretação dela, que se tornou dominante na cultura europeia contemporânea, qual seja, a compreensão da justiça como um em si, uma essência (ponto este que a segunda dissertação da Genealogia da moral enfatiza), até mesmo como a expressão do mundo verdadeiro e da legalidade que o rege. Em resumo, a justiça identificada a uma ordem transcendente, referendada, por exemplo, pela sabedoria divina. $\mathrm{O}$ racionalismo metafísico pensou a justiça comumente nesta direção. A definição que Leibniz fornece da justiça é exemplar: "a justiça, num sentido forte, é apenas a bondade conforme a sabedoria"s. A justiça encontra-se, portanto, reenviada à ordem das perfeições divinas, donde sua identificação à caridade em alguns dos textos de Leibniz ${ }^{6}$. Em outros textos encontram-se uma versão secularizada desta maneira de pensar, vigorosa na época contemporânea, na qual a referência a Deus ou ao transcendente é substituída pela ideia de igualdade universal: a justiça como igualdade de todos, como igualdade de direitos para todos. A proximidade destas duas variantes se traduz no fato de que elas condenam o mundo sensível existente, considerando-o inapto a realizar de maneira efetiva esta justiça, que seria profundamente injusta, devendo ser corrigida.

Nietzsche mostrará que esta tendência é ilegítima e perigosa, recusando pensar este mundo, terreno, como injusto, e recusando remeter o justo ao divino, ao suprassensível ou ao ideal (a igualdade para todos). O filósofo pretende, por sua vez, atribuir a inocência ao vir a ser, de forma que, ao pensar o verdadeiro sentido da justiça, seja possível promover uma defesa da realidade contra seus acusadores ${ }^{7}$. Assim, será necessário evidenciar as tendências

5 Princípios da natureza e da graça, §9. Nietzsche afirmará, veremos, "sabedoria conforme a potência".

6 Veja, por exemplo, o texto inédito publicado por G. Grua: "LA JUSTICE est la charité conforme à la sagesse" (LEIBNZ. Textes inédits. Paris: PUF, 1948, t.2, p. 583).

7 Veja, por exemplo, Nachlass/FP 1888 15[30], KSA 13.422-6. 
Wotling, P.

pulsionais que governam aqueles que defendem esta interpretação da justiça (isto é, as pulsões que se exprimem no cristianismo ou ainda naquilo que Nietzsche denomina de "o socialismo"). Procedendo desse modo, chegar-se-á à conclusão de que o sentido de justiça é fundamentalmente psicológico: é no campo das relações entre pulsões que a noção de justiça encontra, inicialmente, sua pertinência; o valor jurídico é apenas o desenvolvimento das pulsões no nível das relações macroscópicas entre indivíduo e comunidade ou entre comunidades.

Comecemos então pelo exame do primeiro sentido, aquele da justiça humana enquanto imposição às relações inter-humanas. Para compreender o que designa justiça, não basta abordar esta ideia de uma maneira abstrata. As determinações de um fenômeno são frequentemente opacas se consideradas de maneira sincrônica (“a forma é fluida, mas o "sentido' é mais ainda", sublinha a Genealogia da moral (GM/GM II 2, KSA 5.293-4); apenas uma investigação diacrônica, que levam em conta a sua constituição, revelam a sua realidade. Em conformidade com a metodologia que defende, Nietzsche promove assim uma verdadeira genealogia da justiça. Em relação a este primeiro ponto, convém relembrar rapidamente as duas dimensões disto que Nietzsche procura pensar pelo viés genealógico $^{8}$. Opondo-se, em primeiro lugar, à tradicional procura pela essência e, de certa maneira, desqualificando toda ideia de um dado sem origem, a genealogia é incialmente pesquisa regressiva, que visa a identificar as origens produtoras de um valor, de uma interpretação ou de um processo (moral, religioso, filosófico ou outro qualquer), isto é, identificar as pulsões que lhe deram nascimento; ela é, em segundo lugar, uma pesquisa sobre os valores dos valores assim detectados. $\mathrm{O}$ primeiro momento não sendo o alvo da investigação, mas a condição que torna possível o segundo.

8 Veja o texto de referência sobre este problema: o prefácio da Genealogia da moral, § 6 (GM/ GM, prefácio, 6, KSA 5.252-5). 
Lembremos que é preciso estar atento a este termo valor, que não possui o mesmo sentido nas duas ocorrências da fórmula: se a primeira visa ao caráter benéfico ou nefasto de um instante, a segunda ocorrência, por sua vez, concerne ao valor enquanto preferência fundamental, sacralizado por uma forma particular de vida (por exemplo, a santificação da verdade ou do bem, no caso de nossa cultura), isto é, uma representação ou uma crença interiorizada, tornada consciente, mas exercendo uma função reguladora da vida humana - e promovendo a partir deste fato um tipo de vida. Estas duas dimensões da pesquisa genealógica se reencontram na exposição de Nietzsche, como poderemos ver.

A ideia fundamental com que Nietzsche trabalha é que a justiça é um resultado, a realização de um processo complexo, e, enquanto tal, possui origens produtoras - de pulsões - que devem ser identificadas. É por essa razão que é necessário começar pela problemática que desenvolve na segunda dissertação da Genealogia da moral, a saber, a elucidação dos principais fenômenos morais, isto é, para ser mais preciso, dos principais fenômenos que a tradição filosófica considera como morais, como relevantes de uma esfera específica da moral. Nietzsche pretende assim mostrar duas coisas: de um lado, que não há especificidade, nem mesmo autonomia, na esfera da moral; de outro, que os fenômenos visados pelos conceitos morais (donde a justiça) são reais, mas se deixam elucidar a partir da lógica da vontade de potência, que regula própria vida: a moral não está numa esfera fora da vida, mas é uma de suas formas.

Isto posto, o elemento principal desta pesquisa é o estatuto do sentimento de culpa e de castigo. Encontra-se aqui uma primeira reviravolta: de certa maneira, não é a justiça que se antecede ao castigo, legitimando-o. É a análise do castigo que leva, inversamente, à via da justiça. Noutras palavras, somente a partir de uma reflexão sobre as origens do sentimento de culpa e do sentido do castigo pode-se adequadamente compreender o surgimento progressivo da justiça, que, por sua vez, faz parte destas coisas "aparentadas" à 
Wotling, P.

culpa e ao castigo, segundo o termo mesmo utilizado no título da segunda dissertação da Genealogia da moral.

Sabe-se que a lógica da investigação realizada na segunda dissertação da Genealogia da moral repousa sobre a apresentação de um modelo de inteligibilidade, do direto das obrigações: um modelo econômico-jurídico de troca, no qual a culpa é percebida originalmente como uma dívida. Para tanto, Nietzsche se apoia principalmente no estudo da linguagem e da evolução semântica: o sentido basilar da "culpa" (Schuld) é o de "dívidas" (Schulden). Supondo, de certa maneira, o modelo do contrato, tudo indica que a relação fundamental das relações inter-humanas se dá entre o credor e o devedor. Se se segue a lógica que este modelo implica, o criminoso, aquele que comete uma falta, é percebido como um devedor, como um indivíduo que se torna culpado de uma dívida. Desse modo, o castigo torna-se interpretável como a compensação que se exige para um dano sofrido. $\mathrm{O}$ processo no seu conjunto revela assim uma troca desta natureza.

Desta análise, Nietzsche retira as suas primeiras conclusões, por meio das quais se começa a ver o que é propriamente a ideia de justiça. Primeiro elemento: antes de tudo, a constituição da justiça garante a generalização da ideia de compensação possível ou a eliminação da ideia de exceção. É a partir do momento onde se impõe a ideia de que nada é sem preço, de que nada é sem medida ou sem equivalente, que nenhuma perda, tão dolorosa que ela possa ser, que nenhum ato, tão grave que ele seja, não são definitivamente irreversíveis - é a partir deste momento que é posta a condição essencial da justiça, que, primeiramente, reestabelece a ideia de universalidade da troca no interior de uma determinada comunidade, de modo que, para toda situação de ataque, de danos, de conflito, seja possível encontrar um arranjo. Deve-se insistir nesta situação que constitui uma verdadeira condição de possibilidade: o início da justiça garante a universalização da relação contratual, como assevera, aliás, o final do $\S 8$ da segunda dissertação da Genealogia $d a$ moral: "cada coisa tem seu preço" (GM/GM II 8, KSA 5.298-300, 
trad. RRTF). Noutros termos, a criação de um sistema de equivalências e de compensações - a regulação das trocas - é o terreno no qual vai se desenvolver, em certas condições, um processo original.

Mas estas observações não são ainda suficientes. A justiça aparece apenas como modificações do castigo num caso específico, qual seja, aquele onde o conflito opõe adversários de mesma potência ou de potência semelhante. Este ponto, que constitui o verdadeiro nascimento da justiça, exige algumas precisões. Deve-se acrescentar a este pilar fundamental, que é a generalização da compensação, uma segunda determinação que concerne à preeminência da ideia do todo, cada vez mais asseverada, qual seja, a de que o dano infligido ao indivíduo seja considerado um dano à comunidade no seu conjunto. Assim, a lógica do todo substitui claramente a lógica das partes, das relações "privadas" entre membros da comunidade. Esta tese repousa sobre uma outra consideração empírica, necessariamente parcial, da história originária das comunidades humanas. Nietzsche se esforça para justificá-la, identificando o mecanismo que a anima, a saber, a apreciação dos graus de potência e suas variações. É porque se leva em conta a potência do conjunto da comunidade - que, por sua vez, avalia os riscos que implica para ela própria um conflito entre as partes - que a justiça, como arranjo, intervém nos casos onde nenhuma saída viável do conflito ocorreria sem o enfrentamento direto e o exercício das represálias ou a guerra. O perigo então é bem aquele de um prolongamento indefinido do conflito, até mesmo de sua extensão, portanto, de uma multiplicação dos danos. Eis onde aparece o risco para o todo: o risco de enfraquecimento generalizado, de dissolução ou de anarquia, entendida como destruição do laço organizador da comunidade. E é aqui que se justifica esta determinação capital, de que a justiça só tem lugar entre partes de potências comparáveis, que se resignam ou são coagidas a compor uma autoridade superior, qual seja, a comunidade a qual elas pertencem - o que corresponde aos dois casos inicialmente distinguidos. Nietzsche insiste neste ponto desde suas primeiras análises do fenômeno na época de Humano, demasiado humano: 
Wotling, P.

Origem da justiça - A justiça (equidade) tem sua origem entre aqueles que têm potência mais ou menos igual, como Tucídides (no terrível diálogo entre os enviados atenienses e mélios) o concebeu corretamente: onde não há nenhuma supremacia claramente reconhecível e um combate se tornaria um inconsequente dano mútuo, surge o pensamento de se entender e negociar as pretensões de ambos os lados; o caráter de troca é o caráter inicial da justiça. Cada um contenta o outro, na medida em que cada um obtém o que estima mais do que o outro. Dá-se a cada um o que ele quer ter, como doravante seu, e se recebe em compensação o que se deseja. Justiça é, portanto, retribuição e intercâmbio, sob a pressuposição de uma posição mais ou menos igual de potência; assim a vingança pertence originalmente ao domínio da justiça, ela é intercâmbio. Assim também a gratidão. - Justiça remete naturalmente ao ponto de vista de uma autoconservação inteligente, portanto, ao egoísmo daquela reflexão: "Para que haveria eu de danificar-me inutilmente e talvez nem sequer alcançar o meu alvo?" - Isso quanto à origem da justiça (MA I/HH I 92, KSA 2.89-90, trad. RRTF) 9

\section{É necessário se deter alguns instantes na referência a Tucídi- des para esclarecer a argumentação de Nietzsche, que evoca o cé- lebre diálogo entre os antenienses e os mélios no final do V livro, no curso do décimo ano de guerra. Mélos decide permanecer neutra,}

9 Compare-se este texto com o $\$ 22$ da segunda parte de Humano, demasiado humano II ("O andarilho e sua sombra"): "Princípio de equilíbrio". O final deste $§ 92$ merece igualmente ser levado em consideração. Ele indica em que a intepretação moral da justiça e, em particular, sua assimilação à esfera do desinteresse, constitui uma distorção da leitura que deixa escapar a lógica específica do fenômeno: "Dado que os homens, conforme o seu hábito intelectual, esqueceram a finalidade original das ações denominadas justas e equitativas, e especialmente porque durante milênios as crianças foram ensinadas a admirar e imitar essas ações, aos poucos formou-se a aparência de que uma ação justa é uma ação altruísta; mas nesta aparência se baseia a alta valorização que ela tem, a qual, como todas as valorizações, está sempre em desenvolvimento: pois algo altamente valorizado é buscado, imitado, multiplicado com sacrifício, e se desenvolve porque o valor do esforço e do zelo de cada indivíduo é também acrescido ao valor da coisa estimada. - Quão pouco moral pareceria o mundo sem o esquecimento! Um poeta poderia dizer que Deus instalou o esquecimento como guardião na soleira do tempo da dignidade humana". 
mesmo não sendo conveniente aos atenienses, que temem que esta situação de exceção, de independência com respeito ao seu império marítimo, possa ser percebida como um signo de fraqueza de sua parte. Nesta contenda, os mélios se indignam com o desiquilíbrio que impõem de supetão os negociadores atenienses, que apenas lhes deixam a escolha entre a guerra e a servidão. É nesta ocasião que os atenienses opõem os dikaia e os dunata, as coisas justas e as coisas possíveis, suscetíveis de futuro. Ora, o critério que justifica a oposição opera em termos de comparação de potência. A consideração dos dikaia intervém quando há igualdade; os dunata ordenam, ao contrário, as situações onde há fortes e fracos (e não iguais), isto é, onde há grande disparidade de potência: "pois, vocês sabem com nós: se o direito intervém nas apreciações humanas para inspirar uma decisão quando as pressões se equivalem, o possível estabelece, ao contrário, a ação dos mais fortes e a aceitação dos fracos"10. Se se der crédito ao discurso de Tucídides, a reinvindicação de justiça dos mélios terá sua pertinência ignorada em razão da desproporção de potência entre os adversários.

Evoquemos brevemente o fim do episódio, narrado de maneira extremamente lacônica por Tucídides, como se ele quisesse sublinhar a brutalidade da política ateniense e seu acordo, terrível, com a análise já enunciada. Depois de uma tentativa de resistência da parte dos habitantes da ilha de Mélos, os atenienses tomaram a cidade, mataram todos os homens em idade de portar armas e venderam as mulheres e as crianças como escravas.

O texto de Tucídides é certamente condensado e difícil. Ocupamo-nos, no presente caso, não da pertinência que possa haver a leitura de tal texto, mas apenas da interpretação que Nietzsche dá à fórmula emprestada dos negociadores atenienses. A observação de Tucídides coloca-se, em todo caso, como um modelo de

10 Histoire de la guerre du Péloponnèse, 1. V. Trad. J. de Romilly, Paris: Les Belles Lettres, t.3, p. 166. Nesta passagem, o "direito" designa os dikaia, as coisas justas; o "possível”, os dunata. 
Wotling, P.

inteligibilidade, que permitirá a Nietzsche condensar as implicações da justiça nesta fórmula, que reaparece muitas vezes nos seus escritos, e, separada de sua base argumentativa, parece não ceder em nada à brutalidade ateniense: "Ao igual o igual, ao desigual o desigual - é assim que nos fala a justiça. E o que segue daí: nunca tornar igual o desigual" (Nachalass/FP 1888 15[118], KSA $13.477-80)^{11}$.

Estas duas primeiras determinações não esgotam ainda o sentido da justiça. Um terceiro elemento precisa ser apresentado: $a$ despersonalização progressiva e a espiritualização da troca. A coerção imposta - que representa a justiça - preocupa-se notadamente em eliminar os efeitos da implicação pessoal e subjetiva. Nisto, a justiça constitui um esforço em direção à objetividade. Esta ideia de equivalência, que deve ordenar as trocas, é, afirma Nietzsche, o início de toda "boa vontade", de toda "equidade", e, mesmo, de toda "objetividade" (cf. GM/GM II 8, KSA 5.305-307). Por que este aparecimento da objetividade, da imparcialidade, que de fato ligamos no mais das vezes à ideia de justiça? Porque esta imposição da obrigação de se entender, aceitando uma compensação, tem por objetivo, bem mais do que reparar, afrontar a violência do afeto de cólera, de vingança, em suma, de tudo o que, reunido, constitui o ressentimento. Nietzsche relembra no $§ 4$ da segunda dissertação da Genealogia da moral que, de início, o castigo, a justiça sob sua forma embrionária, ou disto donde a justiça acabará por surgir, é uma mistura de afeto violento (a cólera a respeito do autor do dano) e a ideia de equivalência. $E$ ele insiste sobre o ponto de que a ideia de equivalência possível modera a virulência da reação passional. É bem esta convicção da universalidade das trocas possíveis, que representa o fator de moderação que permite combater a tirania das pulsões por represálias. Ela fornece, com efeito, um meio de combater o arbitrário do indivíduo (cf. GM/GM II 11, KSA 5.309-313):

11 Ver também a este respeito, Crepúsculo dos ídolos, "Incursões de um extemporâneo", § 48. 
uma das técnicas para isso consiste, em particular, em separar o criminoso de seu ato (cf. GM/GM II 10, KSA 5.308-9), como forma de evitar que ele não seja identificado por inteiro pela vítima do dano que ele causou. Esta superpersonalização levaria a uma lógica de luta até a morte, de enfrentamento sem termo (há a despersonalização do lado do autor do dano, assim como a limitação da explosão afetiva é uma despersonalização da parte da vítima):

Em toda parte onde se exerce e se mantém a justiça, vemos um poder mais forte que busca meios de pôr fim, entre os mais fracos a ele subordinados (grupos ou indivíduos), ao insensato influxo do ressentimento, seja retirando das mãos da vingança o objeto do ressentimento, seja colocando em lugar da vingança a luta contra os inimigos da paz e da ordem, seja imaginando, sugerindo ou mesmo forçando compromissos, seja elevando certos equivalentes de prejuízos à categoria de norma, à qual de uma vez por todas passa a ser dirigido o ressentimento (GM/GM II 11, KSA 5.309-313).

Se tomamos uma certa distância e consideramos a generalização destas técnicas, vemos que o móvel fundamental da justiça, segundo a análise que fornece Nietzsche, é a instauração da lei do direito. A justiça não deve ser pensada como a obediência às leis, mas, ao contrário, ela surge como condição de instauração da lei. Nietzsche reencontra aqui uma das problemáticas que guiava os debates sobre a justiça no pensamento antigo e opõe-se, em particular, a certas posições de Platão (sobretudo no Críton, mas também, numa medida menor, nas Leis, em particular o VI livro) e de Aristóteles (pensamos na análise geral da justiça no V livro da Ética a Nicômaco). Mas o ponto mais original e, sem dúvida, o mais importante, é este em que as análises indicam claramente a distância que Nietzsche toma de Cálicles: a lei não é uma necessidade dos fracos para inibir a potência dos fortes, mas, ao contrário, uma necessidade imperiosa dos fortes, dos representantes dos mais altos graus de potência para impedir os menos fortes de não infringir 
a segurança e a potência do todo. A reviravolta desta análise aqui apresentada é espetacular.

Resumamos o nosso percurso. A ideia capital consiste em despersonalizar as relações, de maneira a atenuar a violência reativa da vítima do dano. Neste sentido, a justiça é uma imposição de uma medida no duplo sentido do termo: moderação da reação, mas também norma, que será aquela do todo e não mais aquela da paixão individual, em geral desenfreada. E é justamente neste momento que podemos falar de um trabalho de espiritualização, isto é, de deslocamento da força bruta, imediata, irrefletida, por atitudes de substituição inventivas, inteligentes, que permitem às pulsões se exprimir, mas desarmando o risco de outrora à comunidade no seu conjunto. Graças a este deslocamento das manifestações pulsionais e afetivas, esta justiça termina por atingir o inverso disto que quer a vingança, como indica a Genealogia da moral:

Mas o decisivo no que a autoridade suprema faz e impõe contra a vigência dos sentimentos de reação e rancor - o que faz sempre, tão logo se sente forte $o$ bastante -, é a instituição da lei, a declaração imperativa sobre o que a seus olhos é permitido, justo e proibido, injusto: após a instituição da lei, ao tratar abusos e atos arbitrários de indivíduos ou grupos inteiros como ofensas à lei, como revoltas contra a autoridade mesma, ela desvia os sentimentos dos seus subordinados do dano imediato causado por tais ofensas, e assim consegue afinal o oposto do que deseja a vingança, a qual enxerga e faz valer somente o ponto de vista do prejudicado -: daí em diante o olho é treinado para uma avaliação sempre mais impessoal do ato, até mesmo o olho do prejudicado (mas este por último, como já se observou) (GM/GM II 11, KSA 5.309-313, trad. PCS).

Resta compreender uma quarta determinação, virtualmente já posta nas etapas precedentes: a preeminência da lógica da potência. Viu-se que são os riscos de certos conflitos que podem ser infligidos à comunidade que condiciona o surgimento da justiça (conflitos entre potências equivalentes, suscetíveis de infligir 
mutualmente danos consideráveis sem que nenhum vencedor consiga se impor; conflitos entre partes no seio do todo). Tratam-se, portanto, de considerações de potência; a despersonalização, imposta cada vez mais fortemente, está a serviço desta lógica da potência, sempre a partir do ponto de vista do todo.

Há avaliação da relação de potência entre os complexos de instintos então considerados e há intepretação antecipadora das consequências de um eventual conflito direto, isto é, apreciação dos danos potenciais para uma e outra parte. Estamos aqui no estrito quadro do exercício da vontade de potência enquanto atividade interpretativa.

Mas resulta desta avaliação particular a suspensão de qualquer natureza da vontade de disciplinar e dominar diretamente o adversário num conflito frontal. A justiça não é, portanto, nada de desinteressado; não há nada aqui de neutralidade desinteressada, de imparcialidade absoluta ${ }^{12}$. Ela não é também igualdade universal, mas igualdade parcial - entre duas comunidades ou entre dois indivíduos. Portanto, a justiça consiste fundamentalmente a se preservar de uma manifestação bruta e direta da força, não pela moralidade, mas por prudência. É nisto que ela manifesta o que se pode chamar de sabedoria na força, ou ainda, "a razão na força", para retomar um título de Aurora. Nisto, ela é sempre uma manifestação da potência, mas uma manifestação espiritualizada, sublimada. Relembremos que, por "espiritualização" (Vergeistigung), Nietzsche designa o "casamento com o espírito", segundo a fórmula do Crepúsculo dos ídolos ${ }^{13}$. Essa noção designa assim um modo de tratamento original das pulsões, opondo-se à manifestação instantânea, direta e violenta - portanto, cega das pulsões. Nisto que nos ocupa, é necessário falar de espiritualização na medida em que intervém a inteligência, a razão, ou ainda, se se quer, a sabedoria:

12 Ver a este respeito Humano, demanisado humano I $\$ 92$.

13 Ver principalmente o capítulo "A moral como contranatureza" $§ 1$ (KSA 6.82-3). 
Wotling, P.

lida-se com uma visão prospectiva, com uma antecipação, que se caracteriza por se levar em conta a duração e que, portanto, se distingue completamente da explosão instantânea da violência, provocada por situação dada, absolutamente cega às consequências. "Sendo a justiça como função de potência de visão muito mais abrangente, que vê além das pequenas perspectivas de bem e mal, tendo portanto um horizonte mais amplo de vantagem - a intenção de obter algo que é mais do que essa e aquela pessoa" (Nachlass/ FP 26[149], KSA 11.188, trad. Flávio Kothe modificada).

O ponto mais importante a se atentar é que se a manifestação for deslocada, não deixará de se tratar do mesmo processo e da mesma lógica. É com a finalidade de preservar a sua potência e de se dar os meios de intensificá-la (tal é a lógica da vontade de potência) que cada um dos adversários faz a escolha de compor. $A$ justiça aparece, em última análise, como uma técnica espiritualizada do exercício da vontade de potência - uma de suas estratégias mais sutis e mais complexas sem nenhuma dúvida. Sobre isto, um ponto tem de ser precisado: poderia se perguntar o que permite a manutenção da intensificação de potência. A Genealogia da moral explica de modo detalhado (cf. GM/GM II 11, KSA 5.309-313): nisto que a justiça permite a formação de complexos de potências mais amplos, maiores - de modo que uma nova unidade se constitui de alguma maneira por meio do arranjo mútuo - se edifica a possibilidade de uma nova aliança ou coalisão. É preciso acrescentar que é este primado da lógica do sentimento de potência que obriga o abandono da ideia de justiça como sendo uma balança na mão que permite que os pratos se equilibrem em favor da imagem da justiça em pé numa balança, forçando os pratos a se equilibrarem.

Precisemos um último ponto a propósito desta ideia de espiritualização. Tratando-se das relações entre os indivíduos no seio de uma mesma comunidade, a justiça apareceria como uma forma evoluída da lógica do castigo, uma forma espiritualizada própria aos altos graus do sentimento de potência. Uma formulação da época da Gaia ciência expressa bem esse trabalho de espiritualização: 
“o juiz é um carrasco sublimado" (Nachlass/FP 1885 11[100], KSA 9.477). Assim, Nietzsche imagina, como hipótese, a maximização deste estado de coisa: tal seria o caso de uma sociedade que conhecesse uma expansão considerável da potência, que caminharia junto a uma intensificação do sentimento de segurança tão potente, que a justiça consistiria em acordar a impunidade ao criminoso (cf. GM/GM II 10, KSA 5.308-9): pois o sentimento de potência seria tal que ela não ressentiria mais os danos suscetíveis de lhe serem infligidos como um verdadeiro perigo. Esta forma brutalmente espiritualizada da justiça seria a graça - a autossupressão da justiça no sentido ordinário.

As análises precedentes foram um esforço para reunir as determinações fundamentais da ideia nietzschiana de justiça. Será possível prolongar esta investigação identificando o que, a título de consequência, encontra-se excluído desta noção. No quadro necessariamente limitado deste estudo, iremos nos deter em duas observações. $\mathrm{O}$ que é rejeitado a partir de um exame histórico preciso (o início da história humana, o estudo das primeiras comunidades humanas) é a ideia da responsabilidade: a justiça não é fundamentalmente um trabalho de identificação de responsabilidades (Nietzsche critica aqui Paul Rée, em sua obra Da origem dos sentimentos morais, que procurava explicar o castigo e o sentimento de justiça a partir da ideia que o criminoso teria podido agir de outro modo, pois responsável por seu ato). $\mathrm{O}$ erro é aqui histórico e sobretudo psicológico: as distinções em termos de responsabilidade são distinções tardias, muitos evoluídas; elas não correspondem à regulação psicológica primária da vida humana, que diz respeito antes de tudo à avaliação das disparidades de potência.

A segunda observação permitirá voltar a uma das orientações críticas anunciadas no início deste trabalho. Se Nietzsche procura mostrar que a justiça se constitui, efetivamente, numa troca de potência que visa a conservar, por um certo tempo, uma situação de equilíbrio, ele mostra ao mesmo tempo que ela não possui uma essência universal: ela está sempre limitada pelas condições de 
Wotling, P.

equilíbrio de potência, como explica o $§ 26$ do $O$ andarilho e sua sombra, intitulado, "Estados de direito como meios":

$\mathrm{O}$ direito, baseando-se em acordos entre iguais, exige enquanto o poder dos que fizeram os acordos permanece igual ou semelhante; ele foi criado pela prudência, para pôr fim à luta e à dissipação inútil entre poderes semelhantes. Mas essa têm um fim igualmente definitivo quando uma das partes se torna decisivamente mais fraca do que a outra: então ocorre submissão e o direito cessa, mas o êxito é o mesmo que até então foi alcançado como o direito. Pois é a prudência do vencedor que aconselha a poupar a força do submisso e não desperdiçá-la inutilmente: e com frequência a situação deste é mais vantajosa do que era a do igual. - Portanto, estados de direito são meios temporários que a prudência aconselha, não são fins (WS/AS 26, KSA 2.560, trad. PCS).

Aqui é preciso retornar alguns passos. Pode-se ter a impressão de que Nietzsche introduz arbitrariamente o modelo de inteligibilidade que constitui o direito das obrigações. Ora, ele apresenta, na verdade, um trabalho de justificação aprofundado: este último repousa na teoria da medida apresentada no $\S 8$ da segunda dissertação da Genealogia da moral. É crucial notar que tanto n'O andarilho e sua sombra (WS/AS 21, KSA 2.554) como na Genealogia da moral, Nietzsche relembra que o homem mede antes de passar à análise da justiça: o homem é um animal que mede, que estabelece equivalências - fundamentalmente, o homem é uma organização de instintos, cada instinto é uma manifestação particular da vontade de potência. O que o homem mede, por consequência, é aquilo que é objeto de toda percepção elementar das pulsões, de toda interpretação elementar da vontade de potência: as variações do sentimento de potência. No quadro do estudo do castigo, o exercício da crueldade era tido por uma das formas possíveis de compensação à ruptura do contrato. Ora, sofrimento e prazer nunca são apresentados por Nietzsche como entidades últimas, mas unicamente como signos destas variações: o sofrimento deve ser pensado como signo ou tradução 
afetiva do declínio da força, da diminuição do sentimento de potência; o prazer como signo da interpretação bem sucedida, eficaz, isto é, do aumento do sentimento de potência. Ora, a crueldade, tal qual ela se manifesta no castigo, consiste sempre na imposição de uma disciplina ou de uma forma ao outro (ou a si mesma, aliás), isto é, ela impõe sua própria potência, donde a percepção do aumento do sentimento de potência. Em suma, vê-se que o sofrimento pode funcionar como valor de troca, se se compreende, de um lado, que se trata sempre de avaliar relações e variações de sentimento de potência, e, de outro, se se compreende igualmente que prazer e sofrimento são apenas signos e não fatos ou entidades últimas. $\mathrm{O}$ que descreve toda a segunda dissertação da Genealogia da moral ainda que em linguagem não técnica na maior parte do tempo - é a lógica interpretativa, que é aquela da vontade de potência e à qual os fenômenos morais podem ser reduzidos. Compreende-se nestas condições que o modelo contratual sobre o qual repousa a elucidação da justiça não tem nada de arbitrário, mas reenvia ao coração da experiência do pensamento de Nietzsche e de sua interpretação da realidade como jogo da vontade de potência.

Convém, portanto, insistir nesta análise, pois ela é essencial para apreender as condições de possibilidade da justiça. $\mathrm{O}$ homem é um complexo de instintos que avalia as relações de potência: primeiramente, a intensificação ou a diminuição de seu próprio sentimento de potência, mas também o grau de potência dos outros complexos pulsionais. É a esta determinação que Nietzsche visa quando ele declara num texto póstumo de 1888 que a vontade de potência é um pathos (uma capacidade de ser afetada, profundamente relacional, que só existe enquanto processo elementar de percepções das variações de potência). E a justiça como imposição e confirmação de um equilíbrio supõe um trabalho constante de reavaliação das relações de potência e de suas variações. É preciso lembrar sobre este tema o final do $§ 112$ de Aurora, que merece, aliás, ser lido por completo no quadro de uma análise da ideia de justiça em Nietzsche: 
Wotling, P.

"Onde o direito predomina, um certo estado e grau de potência é mantida, uma diminuição ou aumento é rechaçado. $\mathrm{O}$ direito dos outros é a concessão, feita por nosso sentimento de potência, ao sentimento potência desses outros. Quando a nossa potência mostra-se abalada e quebrantada, cessam os nossos direitos: e, quando nos tornamos muito mais poderosos, cessam os direitos dos outros sobre nós, tal como os havíamos reconhecido a eles até então. - O 'homem justo' requer, continuamente, a fina sensibilidade de uma balança: para os graus de potência e direito, que, dada a natureza transitória das coisas humanas, sempre ficarão em equilíbrio apenas por um instante, geralmente subindo ou descendo: - portanto, ser justo é difícil, e exige muita prática e boa vontade, e muito espírito muito bom“ (M/A 112, KSA 3.100-2, trad. PCS modificada).

Bem entendido, esta avaliação é interpretativa (toda realidade é um jogo de processo de interpretação - lembremos que não há verdade, nem em si; a verdade é apenas uma forma particular da interpretação), por extensão, inevitavelmente deformante; ela recobre, portanto, a possibilidade de uma variação, de um erro de avaliação. E é aí que nasce a distância entre a justiça e o sentimento de justiça ou, mais ainda, de injustiça. O sentimento de injustiça repousa muito frequentemente numa distorção de avaliação, como indica a análise surpreendente oferecida pelo $\S 81$ do primeiro volume de Humano, demasiado humano:

Erros do que sofre e do que age. - Quando o rico toma do pobre um bem (por exemplo, o príncipe toma do plebeu a amada), nasce no pobre um erro; ele pensa que aquele tem de ser totalmente celerado para tomar dele o pouco que ele tem. Mas aquele não sente tão profundamente o valor de um único bem, porque está habituado a ter muitos: assim, não pode ser pôr na alma do pobre e está longe de fazer tanta injustiça quanto este acredita. Ambos têm, um do outo, uma falsa representação. A injustiça do poderoso, a quem mais revolta na história, está longe de ser tão grande como parece. Já o sentimento herdado de ser um ser 
superior com direitos superiores torna devidamente frio e deixa a consciência tranquila: nós mesmos, quando a diferença entre nós e um outro ser é muito grande, não sentimos mais nada de injustiça e matamos uma mosca, por exemplo, sem nenhum remorso na consciência. Assim, não há nenhum sinal de maldade em Xerxes (que, aliás, todos os gregos descrevem como eminentemente nobre) quando toma do pai seu filho e manda despedaçá-lo, porque este manifestara uma medrosa, ominosa desconfiança contra toda a expedição do exército: o indivíduo é nesse caso posto de lado como um inseto desagradável: está baixo demais para poder despertar por mais tempo sentimentos torturantes em um dominador do mudo. Sim, aquele que é cruel não é cruel na media em que o acredita o maltratado; a representação da dor não é o mesmo que o padecimento dela. Assim também se passa com o juiz injusto, com o jornalista que com pequenas deslealdades induz em erro a opinião pública. Causa e efeito são cercados, em todos esses casos, por grupos de sentimento e de pensamento inteiramente diferentes; e no entanto se pressupõe involuntariamente que o que age e o que sofre pensam e sentem igual, e, em conformidade com esse pressuposto, se mede a culpa de um segundo a dor do outro (MA/HH 81, KSA 2.85-6, trad. RRTF).

Este texto, um pouco desconcertante, desvenda um elemento determinante da reflexão nietzschiana sobre a justiça. Esta distorção da avaliação, origem do sentimento de injustiça, constitui um dos fatores que alimentam constantemente o transbordamento da paixão subjetiva e tendem a bloquear as possibilidades de troca no nível de uma lógica de represálias. É por isso, como se viu, que a justiça consiste em impor uma avaliação, uma ordem ou uma medida que são aqueles do todo, da comunidade no seu conjunto. Vários fragmentos póstumos insistem sobre este aspecto da análise, que indica bem a coerência da análise nietzschiana: "O problema da justiça. O primeiro e mais poderoso é justamente a vontade e a energia devotadas ao superpoder. Só o dominante fixa e assegura depois a 'Justiça', ou seja, ele mensura as coisas de acordo com a sua própria escala; se ele é muito poderoso, pode ir muito longe no 
Wotling, P.

tolerar as experiências individuais" (Nachlass/FP 1884 26[359], KSA 11.244-5. Trad. Flávio Kothe modificada). A justiça nasceu quando uma situação global de potência para uma comunidade tornou-se tal que não depende mais da mimética das represálias. Um cálculo ou uma avalição intervém sempre, cada vez mais distante do caso particular, pois mais global: o ponto de vista do todo se impõe progressivamente.

As últimas consequências da elucidação positiva da justiça permitem a Nietzsche criticar ao mesmo tempo uma outra teoria da gênese da justiça, qual seja, aquela que é derivada dos afetos negativos, fortemente reativos, em particular da vontade de vingança e do ressentimento. A justiça poderia ser pensada como espiritualização do ressentimento? Neste ponto, os textos nietzschianos nos incitam a uma dupla investigação: sobre o plano prático, temos a práxis que foi aquela do cristianismo; mas na época contemporânea, um equivalente desta prática efetiva se constitui sob a forma teórica. Nietzsche pensa em particular em Dühring, que ele critica severamente no $§ 11$ da segunda dissertação da Genealogia da moral. De alguma maneira, a via teórica revela ingenuamente as competências que esconde a prática do cristianismo e, de maneira geral, da moral acética.

Nietzsche considera tal interpretação da justiça inadmissível por entendê-la ser filosoficamente inaceitável, pois deforma o texto a ser interpretado, como bem apresenta, em numerosos exemplos, a primeira seção de Para além de bem e mal. A este respeito, debrucemo-nos sobre o caso do cristianismo, objeto de Nietzsche na primeira dissertação da Genealogia da moral: em que há exatamente deformação? Notadamente nisto em que esta doutrina da justiça considera de supetão o sentimento de potência e suas manifestações nos fortes como condenáveis - mas sem justificar os seus pontos de vista de algum modo; mais ainda, nisto que ela introduz fraudulentamente no "texto", o que seja, a ideia de que a força é livre de se manifestar ou não, acrescentando assim ao texto (o agir, a força como processo e os atos dos fortes, aos quais 
é rechaçado sua autoridade até mesmo de violência) um elemento estrangeiro: a ideia de um suporte substancial do agir, que condicionaria o processo do agir. Este é caso de deformação de um texto a ser interpretado, de erro filológico; acréscimo de algo introduzido arbitrariamente no texto, que vai construir finalmente a interpretação do conjunto. Se se segue aqui a análise nietzschiana, esta "leitura" recusa ver que a realidade é vontade de potência, que a intensificação do sentimento de potência é exigência mesma de toda vida, para poder valorizar os graus mais fracos da vida, antes honrados pelo título de "justos". Esta deformação permite construir um novo sentido para as situações de conflito e de enfrentamento; mais ainda, evidencia as pulsões que realizam essa reinterpretação: como se sabe, Nietzsche diagnostica em particular o afeto da vingança (Rachsucht) e o ato do ressentimento (o ódio introduzido, interiorizado, que visa a atingir os dominantes, os aristocratas...). A "justiça" como ressentimento espiritualizado pode ser apenas uma palavra, uma designação honorífica, que não corresponde à realidade do jogo pulsional. Permanecer numa avaliação teórica de sua pertinência e subestimar seu verdadeiro valor, que é de ordem prática, seria um engano: "Para uma crítica das grandes palavras (...) cristianismo, revolução, suspensão da escravidão, direitos iguais, filantropia, amor à paz, justiça, verdade: todas essas grandes palavras só possuem valor na luta, como estandartes: não como realidades, mas como palavras pomposas para designar algo completamente diferente (sim, oposto!)" (Nachlass/FP nov. 1887, mar.1888 11[135], KSA 13.62, trad. Flávio Kothe). Esta interpretação da justiça é uma reinterpretação; é secundária e não originária sua consideração inicial sobre a dominação (pulsional) dos fortes. Ela acompanha um movimento de revolta (donde o caráter reativo que Nietzsche sublinha). É por esta razão que é preciso trazer à baila a lógica da primeira dissertação da Genealogia da moral para restituir a crítica desta compreensão da justiça.

Esta justiça, assim repensada como igualdade universal, como recusa de toda forma hierárquica e, sobretudo, como sanção da 
Wotling, P.

responsabilidade (a responsabilidade é a peça essencial, pois ela permite dar uma aparência de justificação racional ao castigo e à condenação) representa uma forma mascarada da vontade de vingança. É o que diz Zaratustra sobre o jogo das palavras gerecht (justo) e gerächt (vingado): “Ah, como lhes sai mal da boca a palavra 'virtude'! E, quando dizem: 'Sou justo', isto soa sempre como: "Estou vingado"' (Za/ZA II, Dos virtuosos, KSA 4.120-3). Vê-se que Nietzsche está em condições de reconstruir uma genealogia da justiça como máscara do ressentimento e de trazer à luz o sentido da reinvindicação da justiça. Os póstumos de 1887-1888, precisamente, mostram este processo muito complexo que visa a perturbar, e mesmo inverter, as relações de potência existentes numa situação dada - completamente ao contrário da justiça em sentido próprio ${ }^{14}$. Enfim, um último problema deve ser abordado, mais ainda, colocado em toda a sua dimensão, qual seja, aquele do segundo sentido da justiça em Nietzsche e suas relações com a justiça no sentido jurídico.

Examinando de perto as análises precedentes, fica evidente que a justiça humana é apenas um caso particular da justiça - a justiça percebida na escala macroscópica; mas Nietzsche nos indicou que a realidade do processo em curso se desenrolava no nível das relações pulsionais: portanto, existe num patamar mais profundo uma justiça pulsional ou interpulsional, que visa ao acordo e à troca compensatória de potência entre pulsões no interior de um organismo ou de um complexo, que não é necessariamente o

14 Veja, por exemplo, os seguintes textos: "Apesar de toda 'vontade de verdade [Nietzsche evoca aqui o escritor norueguês $H$. Ibsen] não ousou se libertar do ilusionismo moral que diz 'liberdade' e não quer se confessar o que é a liberdade: o segundo grau na metamorfose da 'Vontade de potência' por parte daqueles a quem falta a potência. No primeiro grau, exige-se a justiça daqueles que tem potência. No segundo, diz-se 'liberdade', isto é, quer-se escapar dos potentes. No terceiro, diz-se 'igualdade dos direitos', isto é, quer, enquanto não tenha condições, quer-se impedir também aos competidores um crescimento de potência" (Nachlass/FP 1883 10[66], KSA 12.465); “ (...) enquanto não se tem a potência, quer-se a liberdade. Se a tem, quer-se o predomínio; se não a consegue (se se é demasiado débil para isso), quer-se a justiça, isto é, igual potência" (Nachlass/FP 1883 10[82], KSA 12.502-4). 
homem (este é apenas um tipo particular de complexo pulsional). Desta justiça "elementar", se assim se pode dizer, de tão surpreendente e de tão difícil de ser pensada, Nietzsche fornece um belo exemplo: aquele do conhecimento. Tão inesperado que se possa parecer, o conhecer possui a justiça como condição de possibilidade:

O que significa conhecer? - Non ridere, non lugere, neque detstari, sed intelligere! - diz Espinosa, simples e sublime, como é seu modo. Entretanto: o que é esse intelligere, no último fundamento, senão a forma em que justamente os três primeiros se fazem sentir a nós de uma só vez? Uma resultante dos impulsos, diferentes e contrários entre si, do querer-rir, lamentar, execrar? Antes que seja possível um conhecer, é preciso que cada um desses impulsos tenha apresentado seu ponto de vista unilateral sobre a coisa ou acontecimento; posteriormente surgia o combate dessas unilateralidades e dele às vezes um meio-termo, um apaziguamento, um dar-razão a todos os três lados, uma espécie de justiça e contrato: pois graças à justiça do contrato podem todos esses impulsos afirmar-se na existência e ter razão todos juntos. Nós, que só temos consciência das últimas cenas de reconciliação e cômputos finais desse longo processo, pensamos portanto que intelligere seja algo conciliador, justo, bom algo essencialmente oposto aos impulsos; enquanto é somente uma certa proporção dos impulsos entre si (FW/GC 333, KSA 3.558-9, trad. RRTF).

Nota-se que Nietzsche sublinha aqui a existência de três fases da relação pulsional estudada. Afim que seja possível o processo que percebemos parcialmente em termos de "conhecer", é preciso que as pulsões - senão todas, ao menos as mais potentes no seio do complexo considerado - cheguem a um acordo, a uma "compositio", para retomar um termo que a Genealogia da moral empresta ao direito romano: que cada um consiga satisfazer-se parcialmente sem sufocar os outros. Sem justiça, não há portanto conhecer. Esse processo pulsional pode assim ser estendido, assim como pode permitir compreender a que visa exatamente a justiça 
Wotling, P.

no segundo sentido evocado por Nietzsche: esta justiça, num sentido psicológico, pode ser caracterizada inicialmente de maneira negativa, como atitude de impedir os afetos mais violentos, os mais apaixonados face à coisa ou ao fenômeno que se considere (que se trate de ódio ou simplesmente de amor), como a arte de se afastar da prevenção, seja ela ditada pela atração ou pela repugnância: o amor trai e deforma tanto quanto tanto o ódio. Parece que desta vez, esta análise da justiça coincide com o que Nietzsche nomeia frequentemente de probidade - pois a capacidade de interpretar sem trair, sem impor desvios filológicos, em suma, a atitude de ler encontra-se confrontada com as exigências da filologia, da arte de bem ler.

A análise da justiça reenvia novamente ao terreno psicológico, recobrindo um problema de equilíbrio das pulsões. $\mathrm{O}$ objetivo não é o de eliminação, mas o de moderar as manifestações das pulsões mais ativas de uma situação dada, de fazer com que estas pulsões se limitem mutualmente, e, desse modo, se coordenem para tornar possível uma nova interpretação. Sem dúvida, o ódio e a gozação intervêm, por exemplo, no processo de construção do conhecimento, mas eles não intervêm justamente sob a forma desenfreada, furibunda, exclusiva e incontrolada que caracteriza a interpretação moralizante, cristã, da justiça.

Um dos últimos aforismos de Humano, demasiado humano trata justamente da justiça no sentido psicológico. Este aforismo opõe, seguindo o mesmo registro teórico dos textos da época, a justiça à convicção e ao falso "gênio", que se endereça àqueles que querem convicções:

É certo que há uma espécie bastante diversa de genialidade, a da justiça; e de modo algum posso me resolver a considera-la inferior a uma outra genialidade, seja filosófica, política ou artística. É de sua natureza evitar, com sentida indignação, tudo aquilo que o ofusca e confunde o julgamento acerca das coisas; ela é, portanto, uma adversária das convicções, pois quer dar a cada coisa, viva ou morta, real ou imaginada, o que é seu - e para isso deve conhece-la exatamente; por isso põe cada 
coisa na melhor das luzes e anda à sua volta com olhar cuidadoso. Enfim, dá até mesmo à sua adversária, a cega ou míope 'convicção' (como é chamada pelos homens; as mulheres a chamam de 'fé'), aquilo que é da convicção - em nome da verdade (MA/HH I 636, KSA 2.361-2, trad. PCS).

Desviar-se das convicções, retraduzido no léxico da psicologia própria a Nietzsche, significa conseguir frear as exigências e as sugestões de uma pulsão (ou de um grupo de pulsões em coalisão). Resta uma questão: como isto é possível? No meio de outras pulsões: isto supõe que se seja muito rico (em termos de diversidade das pulsões) e muito forte (em termos de potência relativa das pulsões) para equilibrar firmemente as relações pulsionais. $\mathrm{O}$ estudo desta justiça elementar nos leva ainda uma vez à questão da potência no sentido em que Nietzsche a entende. A justiça designa um meio entre a tirania e a anarquia, isto é, entre a dominação exclusiva de uma pulsão e a dissolução completa do sistema pulsional. É preciso atentar particularmente para a significação desta análise: é que Nietzsche sempre caracteriza a força como o meio entre a tirania e a anarquia. A justiça, enquanto probridade, deve portanto ser pensada como manifestação suprema de força, longe da força bruta, no sentido naturalista de Cálicles. Esta é uma temática recorrente. Um dos textos mais claros a este respeito é um fragmento póstumo da época de Humano, demasiado humano: "Também somos injustos quando encontramos os grandes homens grandes demais e as coisas no mundo profundas demais. Quem quer dar à vida o significado mais profundo, que envolva o mundo em fábulas; estamos todos ainda profundamente envolvidos nele, por mais liberais que pareçamos. Há uma forte tendência, surgida nos tempos mais remotos, de exagerar as distâncias, de carregar nas cores e de tomar o brilhante como mais provável. A força mostra-se principalmente nessa ênfase excessivamente aguda; mas a força na moderação é superior, a justiça é mais difícil do que a abnegação e o amor" (Nachlass/FP final 1876-verão 187723[133], KSA 8.450-1 Trad. Karina Jannini; grifo final do autor]. 
Wotling, P.

Insistamos nesta última determinação: justiça e probidade são signos de um grau elevado de potência. Sobre este ponto insiste a Genealogia da moral ao defender a tese de que a probidade está ao lado da força e não ao da fraqueza reativa:

De ordinário, mesmo para as mais íntegras pessoas basta uma pequena dose de agressão, malícia, insinuação, para lhes fazer o sangue subir aos olhos e a imparcialidade sair dos olhos. $\mathrm{O}$ homem ativo, violento, excessivo, está sempre bem mais próximo da injustiça que o homem reativo; pois ele não necessita em absoluto avaliar seu objeto de modo falso e parcial, como faz, como tem que fazer o homem reativo (GM II 11, KSA 5.309-313, trad. PCS).

É pois um problema de equilíbrio e de hierarquia pulsional que nos conduz, no fim das contas, à interrogação sobre a justiça. Ela revela apenas seu sentido no quadro da lógica da intensificação da potência que é a lógica fundamental da realidade em todas as suas manifestações. É por isso que ela não é para Nietzsche um fenômeno especificamente político ou moral, mas designa fundamentalmente um modo de relação entre quanta de potência - entre pulsões -, como sublinha o $\$ 333$ da Gaia ciência. E é por esta razão que ela se encontra finalmente identificada a um modo de exercício da vontade de potência ${ }^{15}$. Um modo de exercício caracterizado não por seu desinteresse, mas por sua sabedoria, por sua ampla visão, que contrasta de maneira flagrante com as perspectivas estreitas e desprovidas de espírito que constituem o bem e o mal. Da confrontação entre Estados à rivalidade interpuslsional no interior do corpo, apenas muda a escala da potência considerada. A lógica permanece inalterada e a justiça aparece sempre como uma das vias possíveis da marcha de intensificação da potência

15 Ver, por exemplo, Nachlass/FP 2[122], KSA 12 ou ainda 7[24] ("“a justiça como vontade de potência) e 8[7] ("a vontade de potência como origem da justiça"). 
de formações pulsionais mais ou menos complexas, uma via que possui esta especificidade de se confirmar como a mais eficaz nas situações onde o controle direto do adversário se revela impraticável. Como se vê, a justiça é pouco moral. Ela traduz o interesse do todo, isto é, da formação global de dominação no seio da qual aparecem conflitos entre os elementos constituintes. No universo governado pela lógica exclusiva da rivalidade e da concorrência para dominá-la, a noção de justiça permite assim pensar em acordos, em suspensões locais da luta permanecendo paradoxalmente em plena conformidade com a lógica da potência, sem a regulação da realidade - tal como Nietzsche nos apresenta - seja alterada. O que estabelece a pesquisa sobre esta noção é a possibilidade de "contratos" pulsionais em certas situações de potências bem determinadas. E é sobre esta lógica pulsional de arranjo provisório, de compensação e de colaboração mútua que repousa em última análise a justiça humana - a justiça considerada, se se quer, em escala macroscópica. É sempre a lógica da intensificação do sentimento de potência que está em jogo; mas ela se joga aqui de um modo indireto, em função de uma estratégia que mostra em alguma medida a inteligência das pulsões, seu "espírito". A justiça se revela assim ser um desses desvios que toma às vezes a vontade de potência para conseguir manter a possibilidade de sua intensificação. Nesta perspectiva, a determinação fundamental da justiça pressupõe um contrato, uma forma de arranjo e de compromisso entre instâncias de potência comparável - ela é no fim das contas a arte de manter a intensificação de sua potência em situações de início desfavoráveis. Nisto, ela tem o interesse de mostrar de que modo o "espírito" habita a potência, de que modo se encontra a "razão no seio da força" (M/A 548, KSA 318-9), isto é, as formas espiritualizadas da luta pulsional, freando as manifestações brutas e imediatas de conflito, representam a condição de graus supremos de potência. Considerada no nível do indivíduo e de sua regulação interior, a justiça oferece um exemplo notável desta "grande razão", mais sábia que nosso espírito, que é o corpo. 
Wotling, P.

Abstract: In contrast to the traditional view of justice, this work aims to expose the way in which Nietzsche interprets this notion, taking as assessment parameter the doctrine of will to power.

Keywords: Nietzsche - justice - power - spirit - body

\section{referências bibliográficas}

PLATÃO. Gorgias. Trad. M. Canto-Sperber. Paris: GF-Flammarion, 1987.

NIETZSCHE, F. Oeuvres philosophiques complètes. Paris: Gallimar 1968-1997.

. Ainsi parlait Zarathoustra. Trad. G.-A. Goldschmidt. Paris: Livre de poche, 1972.

. Le gai savoir. Trad. Patrick Wotling. Paris: GF-Flammarion, 1997.

. Par-delà bien et mal. Trad. Patrick Wotling. Paris: GF-Frlammarion, 2000.

. Élements pour la généalogie de la morale. Trad. Patrick Wotling. Paris: Livre de Poche, 2000.

. Crépuscule des idoles. Trad. Patrick Wotling. Paris: GF-Flammarion, 2005.

. Obras incompletas. Trad. Rubens Rodrigues Torres Filho. São Paulo: Nova

Cultural, 1986 (Col. "Os Pensadores").

. Assim falava Zaratustra. Trad. Mario da Silva. São Paulo: Bertrand Brasil, 1995

. Humano, demasidado humano. Trad. Paulo César Souza. São Paulo: Cia das

Letras, 2000;

. Humano, demasidado humano II. Trad. Paulo César Souza. São Paulo: Cia das Letras, 2008.

. Genealogia da Moral. Trad. Paulo César Souza. São Paulo: Cia das Letras, 1998.

. Além do bem e do mal. Trad. Paulo César Souza. São Paulo: Cia das Letras, 1996.

THUCYDIDE. Histoire de la guerre du Péloponnèse, 1. Trad. J. de Romilly. Paris: Les Belles Lettres, t.III.

Artigo recebido para publicação em 10/12/2012.

Artigo aceito para publicação em 15/01/2013.

232 | cadernos Nietzsche 32, 2013 


\section{Dossiê "Leituras portuguesas de Nietzsche"}


